\title{
Consumer knowledge and acceptance of agricultural biotechnology vary
}

\author{
Jennifer S. James
}

$\nabla$

Results from consumer surveys reveal some basic conclusions about consumer attitudes toward agricultural biotechnology. First, consumers do not agree about whether biotech foods are good or bad. Second, a small group of people strongly opposes them. Third, the majority of consumers are uninformed about the technology and how food is produced. Relatively small but vocal anti-biotechnology activist groups are successful at influencing public opinion because of consumers' lack of knowledge, creating a role for universities and government agencies to provide clear, objective and accessible information.

he food system is often described as
increasingly consumer-driven, but this does not seem to be the case with food products derived from modern biotechnology. Genetically engineered (GE) crops have been commercially available since 1996, but most consumers are unaware that they have probably been consuming them. Consumer acceptance or rejection of food made from biotech crops can have important economic implications at all levels of the food system (see page 80).

Consumer acceptance (or apathy) would imply that segregation, identity preservation and labeling of biotech foods are not necessary, at least from the consumer's perspective. On the other hand, consumer concerns or reluctance may mean that markets will be lost, ultimately causing adoption rates to decline. In the extreme, consumer concerns may drive policy decisions (as some argue has occurred in the European Union), with the resulting policies imposing costs on producers as well as consumers. Consumer willingness to purchase biotech products also affects the incentives for food retailers to carry them, for food manufacturers to use biotech crops as ingredients, for growers to adopt them, and for life-sciences companies to develop new applications. Furthermore, uncertainty about consumer willingness to purchase biotech products increases risks associated with the adoption, use of and investments in GE crops.

Although consumer preferences could potentially play an important role in the future of agricultural biotechnology, little is known about them. Because biotech products are not labeled in the United States, consumers have not had the opportunity to reveal their preferences. The only way for consumers to avoid biotech foods is to purchase certified organic products, but it is difficult to isolate consumer demand for the nonbiotech trait from the demand for other traits of certified organic foods.

While market data is not available, a fairly extensive body of survey research has been conducted to assess consumer awareness and knowledge of, and attitudes toward biotech products. Stated attitudes are usually used to infer how consumers might respond to, for in-

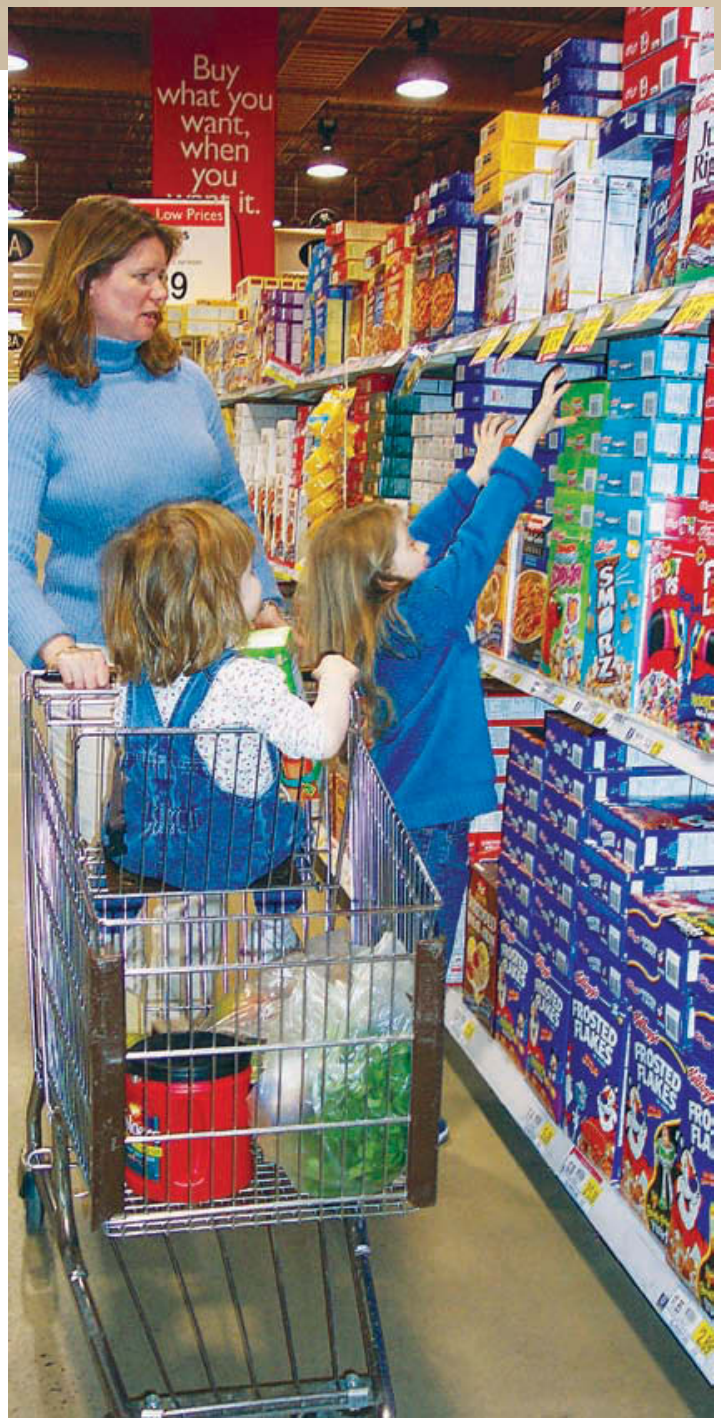

Consumer preferences could play an important role in the future of agricultural biotechnology in the United States.

stance, food labels indicating whether they contain biotech ingredients. This article describes and interprets results from the large and growing number of U.S. national telephone surveys and a few studies using alternative methods, and discusses possible implications for biotech product markets.

\section{A caution regarding survey results}

The survey method has some shortcomings, which serve as a reminder not to read too much into any individual

\section{While some consumers are uninformed or indifferent, the rest are split in favor and against biotech products, with a small share strongly opposed. When asked, most U.S. consumers say biotech products should be labeled.}




\section{Words matter}

\section{Robert Herrmann \\ Rex Warland \\ Arthur Sterngold}

$\mathrm{R}$ esponses to survey questions can be affected by assumptions embedded in the question. A 1994 national survey conducted at Pennsylvania State University demonstrated the effects of such suppositions. The survey asked 1,000 respondents about their food safety concerns; they were divided into four groups of 250 and each group was asked different questions.

Consumers in group 1 were asked "How concerned are you about IMS in seafood?" Fifty-three percent said that they were either somewhat or very concerned, and $30 \%$ said they did not know. The wording of this question implies several underlying assumptions. In particular, this question assumed that the respondent is concerned about IMS, the only question being the degree of concern.

Questions posed to the other three groups included filters designed to reduce the effects of such assumptions.

In group 2, consumers were asked "Are you concerned about IMS in seafood?" If they said yes, they were asked about their level of concern. When this concern filter was used, the proportion of respondents expressing concern decreased to $32 \%$, with $25 \%$ saying they did not know. For groups 1 and 2, the questions assumed that respondents know what IMS is, or have at least heard of it.

In group 3, consumers were asked "Have you ever heard of any health problems associated with IMS in seafood?" When this awareness filter was used, only $24 \%$ of the respondents said that they had heard of health problems, with $65 \%$ saying they had not, and $11 \%$ saying they did not know or weren't sure. Comparing the $24 \%$ who said they had heard of IMS to the $53 \%$ and $32 \%$ expressing concern in groups 1 and 2 suggests that several people who expressed concern in groups 1 and 2 had not heard of IMS.

The wording of questions posed to groups 1, 2 and 3 all assumed that IMS exists. Group 4 combined the awareness and concern filters in order to minimize the effects of the suppositional wording in groups 1, 2 and 3 . In group 4, consumers were asked if they had heard about health problems associated with IMS in seafood. Those who said they had heard of it were asked if they were concerned, and those who were concerned were asked their degree of concern. Even after applying both filters, $18 \%$ of the respondents in group 4 said they were somewhat or very concerned about IMS, a food safety issue that does not exist.

varying proportions of respondents expressing concern about IMS in the four groups shows how results can be affected by question wording. Filters help minimize the tendency for survey respondents to overstate their concerns, but they are seldom used because they slow down questioning and respondents may find them tedious.

\section{R. Herrmann is Professor Emeritus of Agricultural Economics and R. Warland is Professor Emeritus of Rural Sociology, Department of Agricultural Economics and Rural Sociology, Pennsylvania State Uni- versity, University Park, Penn.; and A. Sterngold is Professor of Business, Department of Business Administration, Ly- coming College, Williamsport, Penn.}

\section{Further reading}

Herrmann RO, Sterngold A, Warland RH. 1998. Comparing alternative question forms for assessing consumer concerns. J Cons Affairs 32(1):13-29.

Sterngold A, Warland RH, Herrmann RO. 1994. Do surveys overstate public concerns? Public Opin Quarterly 58(2):255-63. result. To a skeptic, a notable problem in survey results is the degree to which they can be influenced by how questions are worded. Compounding this problem is the fact that the exact wording of questions often is not presented with the results (especially in the popular press), so that it is easy to misinterpret findings or put them in an inappropriate context.

Suppositional wording is a way of asking a question that implies particular assumptions, which in turn affects responses; it has been shown to influence the level of concern expressed by respondents (see sidebar, page 100). In addition, imbedded assumptions can be seen in other types of questions. Information is often provided to respondents along with the questions, and its content and wording can influence responses. In some recent surveys, a definition of biotechnology or genetic engineering was read to respondents. For some respondents, the definition may have been their first exposure to the technology. What they are told can have a pronounced effect on how they answer subsequent questions.

The sensitivity of responses to wording is especially problematic when survey responses are used to infer or predict market behavior. If responses are sensitive to wording, how much can they reveal about choices consumers would make? While it is important to be cautious in interpreting survey responses, when taken together the surveys do tell a fairly consistent story.

\section{Lack of awareness}

One of the most notable regularities in survey responses is the lack of U.S. consumer awareness about agricultural biotechnology. Most studies find that roughly half of those surveyed have heard little or nothing about food produced using biotechnology, genetically modified (GM) foods or genetic engineering. Shanahan et al. (2001) reviewed 12 surveys conducted between 1993 and 2000, and in 10 at least $50 \%$ of the respondents had heard "not much" or "nothing at all" about biotechnology. A Gallup Poll conducted in 2001 found that $40 \%$ had heard "not much" or 
"nothing," down from 50\% in a 1999 survey by the same firm (Saad 2001). A less clear pattern is revealed in three surveys conducted for the Pew Initiative on Food and Biotechnology (2001, 2003), an organization funded by the Pew Charitable Trusts to provide unbiased information and encourage public debate about agricultural biotechnology. In each survey, respondents were asked how much they had "seen, read, or heard recently regarding genetically modified food that is sold in grocery stores." The percentage of respondents who had heard "not too much" or "nothing at all" was 54\% in January 2001, 45\% in June 2001 and $65 \%$ in September 2003. These results cast doubt on the hypothesis that there is any clear trend in awareness, and suggest that awareness may be somewhat temporary, perhaps driven by recent media coverage.

While studies vary, the overwhelming message is that many Americans are unaware of GM foods. This lack of awareness provides another reason to interpret survey data cautiously. The Center for Science in the Public Interest (CSPI) is a nutrition advocacy organization funded by subscriptions to its Nutrition Action Healthletter and by donations from charitable foundations. In a 2001 report, CSPI noted that telephone surveys ask people ques- tions about something they probably do not think about often or may know little or nothing about. Surveys are usually fast-paced, and there is not a lot of time for deliberation. Taking awareness (and knowledge) of respondents into account can help put other responses in perspective. For instance, in the 2001 Pew study, 73\% said they were either "very" or "somewhat" concerned about the recall of taco shells and other corn products containing StarLink corn, a GE variety that was approved for animal feed but not human consumption. However, responses to the previous question put this result in a different light; only $57 \%$ had heard "some" or "a great deal" about the taco shell recalls. So, at least $16 \%$ of the respondents expressed concern about the recall but had not heard much (if anything) about it.

\section{Extent of knowledge}

Many surveys ask respondents to rate the extent of their knowledge or familiarity with biotechnology or genetic engineering. Two studies conducted in 1998 and 2000 found that only about $20 \%$ of respondents said they knew or understood "some" or "a lot" about GM foods (Shanahan et al. 2001). Between 1997 and 2002, several consumer surveys were conducted

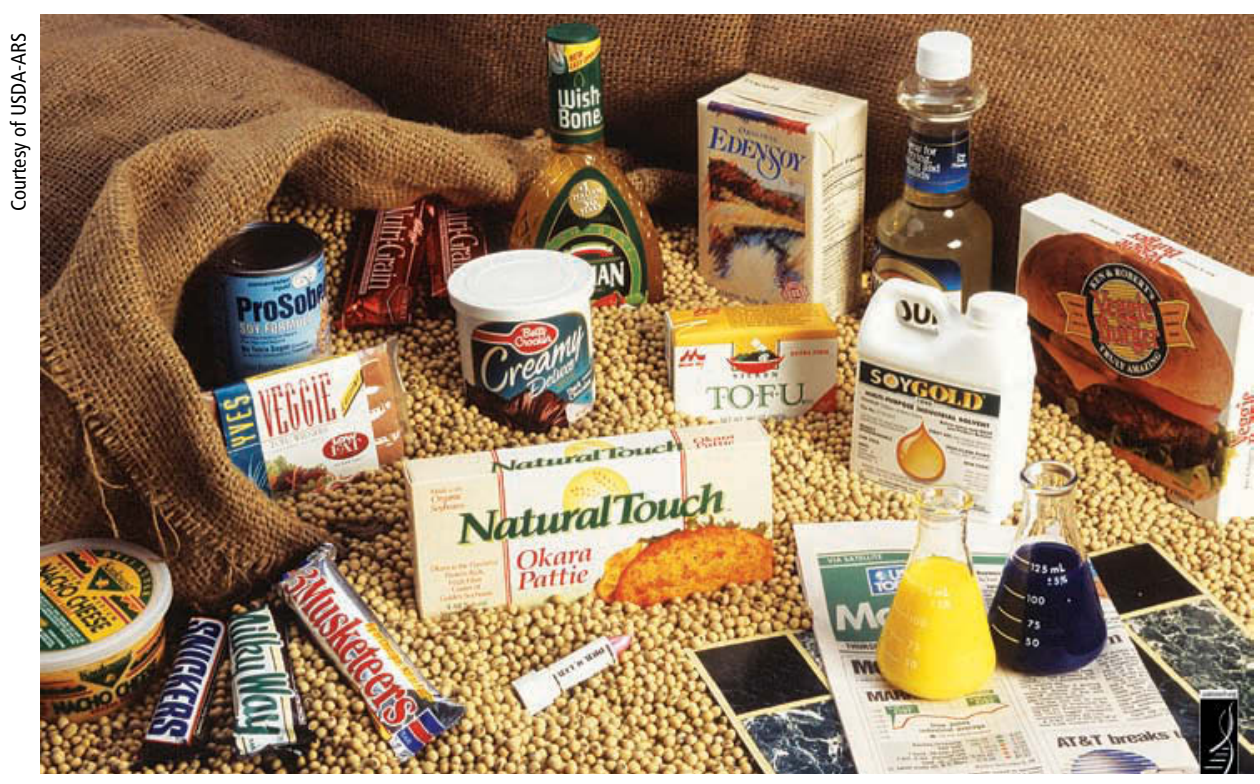

Because genetically engineered cottonseed, canola, corn and soy are common in many processed foods, the percentage of foods in the supermarket with at least one of these ingredients is estimated as high as $75 \%$. But in surveys, many consumers are unaware that they have been eating foods with genetically engineered ingredients.

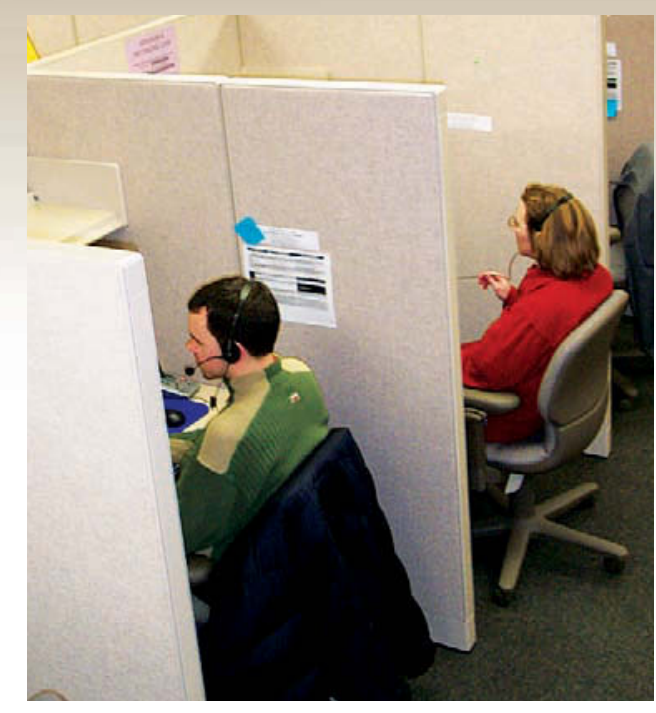

Individual consumer surveys are subject to interpretation, but together they tell a fairly consistent story about attitudes and knowledge of agricultural biotechnology. Above, surveyors question consumers.

for the International Food Information Council (IFIC), an industry-funded organization that provides science-based information on nutrition and health to individuals and groups that communicate with consumers. The IFIC surveys (2003) found a higher proportion of the respondents having read or heard "some" or "a lot" about biotechnology, ranging between $33 \%$ and $47 \%$, with no clear pattern over time.

More general knowledge (or lack of it) about how food is produced is sometimes revealed in the answers to questions that have little to do with biotechnology. The 2001 CSPI survey focused on food labeling. Respondents were asked about labels for a number of product characteristics, in addition to whether a food or its ingredients had been genetically engineered. In this survey, $40 \%$ thought that the words "made from crossbred corn" should appear on the food label if it applies. Further, only $40 \%$ said that they would purchase processed foods that were labeled as having been made from crossbred corn. Since nearly all corn varieties currently being used are crossbred, stated resistance to consuming this type of corn reveals a lack of basic knowledge about agriculture and how food is produced.

Other questions ask whether respondents have ever eaten a biotech product, or whether biotech products are available in grocery stores now. The IFIC studies conducted between 1997 and 2003 each asked "as far as you 


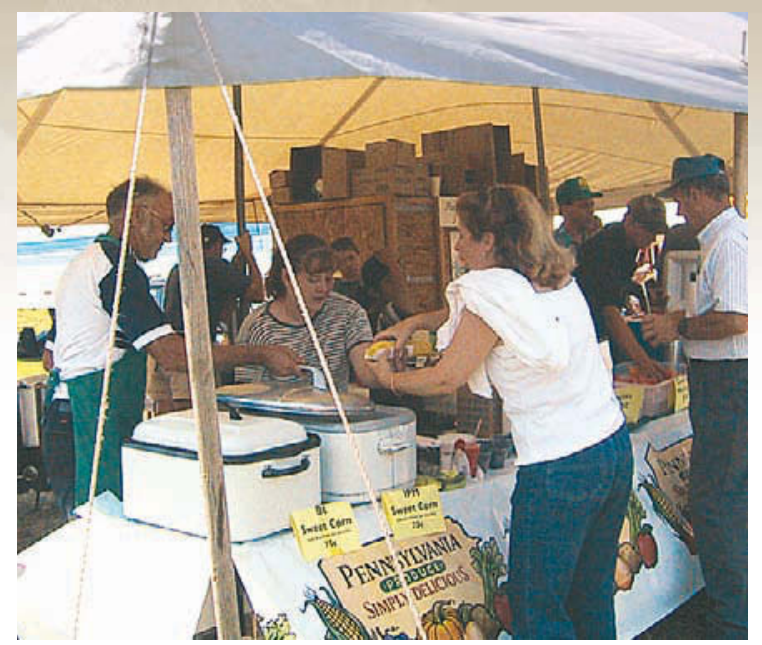

At Pennsylvania State University's Ag Progress Days, Bt sweet corn was offered to consumers alongside corn labeled as "IPM" (grown using integrated pest management), along with informational brochures.

know, are there any foods produced through biotechnology in the supermarket now?" Over the years, "Yes" responses ranged from $33 \%$ to $43 \%$. Although this proportion may seem low, given that roughly two-thirds of the items available at food retailers contain GE ingredients, $33 \%$ is a fairly high proportion for this type of question relative to other studies (perhaps because of the use of "biotechnology," which refers to a broader range of practices relative to "genetic engineering"). In the 2001 Pew study, only 19\% said they had eaten GM foods, $62 \%$ said they had not and 19\% did not know. When asked how many foods in a typical American grocery store they thought were genetically modified, only $14 \%$ of the 2001 Pew respondents thought that over half of the foods contained such ingredients.

\section{Attitudes toward ag biotech}

Questions attempting to assess consumer attitudes toward agricultural biotechnology have been included in many surveys in a number of forms. In some surveys, consumers are asked whether they think the risks outweigh the benefits (or vice versa), whether they support the use of biotechnology to produce food, or whether they think the use of biotechnology in food production will increase the quality of their lives. However, because consumer awareness and knowledge are so low, many respondents are being asked for their opinion about something they have not previously heard of or know little about.
Most surveys address this problem by providing a brief description of biotechnology or genetic engineering. The information provided is often excluded from reports describing results even though it can have an important influence on the responses. One notable example described by Shanahan et al. (2001) is a survey conducted by the Harris Poll in 1993. In a question designed to measure attitudes about the relative risks and benefits of genetic engineering, the dinosaurs in the movie Jurassic Park were given as an example of genetic engineering. The reference to Jurassic Park evokes a very negative image, so it is not surprising that $57 \%$ of respondents said they thought the risks of genetic engineering outweighed the benefits (the most negative response to this type of question in the surveys reviewed by Shanahan et al. 2001).

A similar but much less biased question was included in a series of surveys conducted by the National Science Foundation, an independent government agency that supports scientific and engineering research, as part of its Science and Engineering Indicators. Those surveys indicated that between $44 \%$ and $50 \%$ of respondents view the benefits of genetic engineering (generally, not specific applications to food) as outweighing the risks, while about 33\% to 39\% see the risks as outweighing the benefits (Shanahan et al. 2001). These surveys were conducted between 1985 and 1999, and the responses were fairly consistent over time. The IFIC surveys conducted between 1997 and 2003 show a slight decline in the proportion of respondents who thought that biotechnology would provide benefits within the next 5 years, from $78 \%$ in 1997 to $62 \%$ in 2003.

Given the variety of ways of asking questions about attitudes toward agricultural biotechnology, it is not surprising that results are mixed. The most striking consistency is the lack of consensus. For most attitude questions of this type, responses in favor or against are rarely more than $60 \%$ or much less than $30 \%$. The 2001 Gallup Poll found that while a slight majority (52\%) support the use of biotechnology in food production (38\% opposed), a larger proportion strongly oppose it $(14 \%)$ relative to those who strongly support it (9\%). The 2001 Pew study had similar results, with more respondents (35\%) strongly opposing the introduction of GM food (out of $58 \%$ opposing) than strongly favoring (8\% out of $26 \%$ in favor).

The 2001 Pew study demonstrates some possible implications of asking the relatively uninformed for their assessment of the technology. Over half of the respondents said they had seen, read or heard "not too much" or "nothing at all" about genetic modification or biotechnology. Later in the survey, respondents were asked whether they thought GM foods were basically safe or unsafe, or whether they were not sure. The next question was the same, but this time it was prefaced with "Now, as you may know, more than half of products at the grocery store are produced using some form of biotechnology or genetic modification. Knowing this, do you think ..." Initially, 29\% said biotech products were safe, $25 \%$ said unsafe and $46 \%$ were not sure or did not have an opinion. However, when given the additional information about their availability in stores, over $30 \%$ changed their answer: $48 \%$ said biotech products were safe, $21 \%$ said unsafe and $31 \%$ were uncertain. There are a number of ways to interpret the switches. For instance, $19 \%$ of those who originally said they thought biotech products were unsafe and $37 \%$ of those who were originally unsure switched their answer to safe. This switch could be interpreted as trust in the food regulatory system or food retailers ("if they're selling it, it must be safe"), or as a kind of coping mechanism ("if I've been eating it, it must be safe"). These results suggest that information affects some respondents' attitudes, and that at least $30 \%$ are not committed to a position on the safety of biotech products.

\section{Willingness to purchase}

Willingness to purchase biotech products is often assessed by asking how likely survey respondents would be to purchase or eat a food produced using biotechnology or genetic engi- 


\section{Consumers purchase Bt sweet corn}

neering. The usual caveats apply about the influence of wording; not surprisingly, results are about as mixed as those concerning attitudes. The 2001 Pew study found that $38 \%$ of respondents were willing to eat biotech food, with $54 \%$ unwilling. In the IFIC surveys, about 70\% said they would be willing to purchase biotech foods modified to resist insect damage so that fewer pesticides may be used, while the corresponding proportion is a bit lower (50\% to $60 \%$ ) for food modified to taste better or fresher. In the CSPI study, $40 \%$ to $43 \%$ said they would buy labeled biotech foods (the proportion depending on the type of food), about the same proportions as those who said they would buy food labeled as being produced from crossbred corn. Overall, stated willingness to purchase biotech products is fairly consistent with stated attitudes.

\section{Preferences for labels}

When consumers are asked if foods produced using biotechnology or genetic engineering should be labeled, a majority will say yes, usually around $80 \%$. Eighty-six percent of the respondents to a 2000 Harris Poll survey said they thought biotech food should be labeled. In the 2001 Pew study, 75\% said it was "very" or "somewhat" important that they know whether a product contains biotech ingredients.

In the CSPI study, 70\% said that GE food should be labeled. However, in another question, consumers were given a list of characteristics for a box of Wheaties and asked to pick which one piece of information they would like to see added to its label. Only $17 \%$ chose "contains genetically engineered wheat," while $31 \%$ chose "contains pesticides in minute amounts" and 31\% said they did not know or did not think any new information should be added. While the majority of consumers consistently say they would prefer biotech products to be labeled, this is a top priority for a relatively small group. Further, only $12 \%$ in the CSPI study said they would be
$\mathrm{Bt}$ corn is one of several widely adopted genetically engineered (GE) crops. It contains a gene from a soil bacterium (Bacillus thuringiensis) that causes the corn to produce a protein toxic to European corn borer and other insect pests, essentially building worm control into the corn. This form of pest control reduces pesticide costs and may improve yields; it is especially beneficial for sweet corn, which has higher insecticide loads than most other fresh-market vegetables. Producer benefits from choosing to plant a Bt sweet corn are clear, but uncertainty about consumer willingness to purchase GE corn reduces those benefits.

A study designed to measure consumer preferences for Bt sweet corn was conducted in central Pennsylvania in summer 2001. The goal was to assess consumer willingness to purchase Bt sweet corn and determine how consumers responded to price variations. Two types of corn were grown at the Penn State farm: one contained the Bt gene, and the other was a related variety that had not been genetically engineered. Corn was clearly labeled as either "Bt Sweet Corn" or "IPM Sweet Corn" and sold side-by-side at five stores in central Pennsylvania and at Penn State's Ag Progress Days. The IPM (produced using integrated-pest-management methods) and Bt sweet corn were described briefly in a brochure available to consumers in each store. The relative prices of $\mathrm{Bt}$ and non-Bt corn were varied from location to location and week to week. Retailers were encouraged to set the price of the IPM corn according to market conditions, but were instructed to sell the Bt cultivar at either the same price as the IPM corn, 15\% less or 15\%

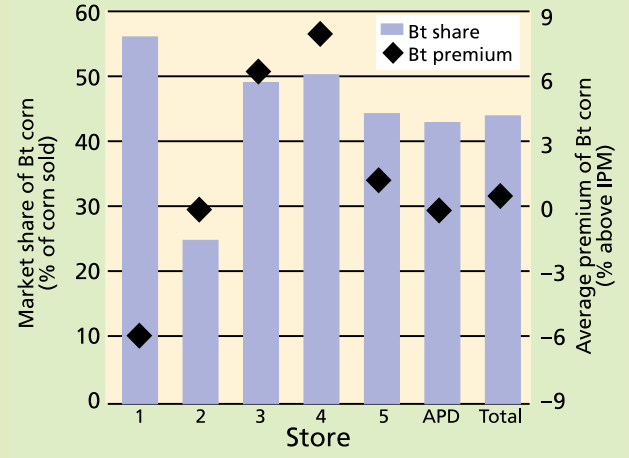

Fig. 1. Market shares (bars, labeled on left axis) and corresponding average price premiums (diamonds, labeled on right axis) for Bt sweet corn by store, plus at Penn State's Ag Progress Days (APD). Corn labeled "Bt Sweet Corn" was sold side-by-side with corn labeled "IPM Sweet Corn"; a brochure explained the difference between the transgenic (Bt) and integrated-pest-management (IPM) products.

more. Sellers recorded how much corn of each type was sold each week.

The results from this geographically specific study cannot be interpreted as nationally representative, but they suggest that there is a viable market for $\mathrm{Bt}$ sweet corn. The overall market share of Bt sweet corn was $44 \%$, shown in figure 1 along with the store-specific market shares. Price seems to have played a fairly minor role in consumer choices, as indicated by the fairly large market shares of Bt sweet-corn in stores 3 and 4, where price premiums were higher, on average, than in other stores. - J.S. James

This study was conducted by J.S. James, Shelby Fleischer, Twilla Parker and Michael Orzolek, Pennsylvania State University, University Park, Penn.

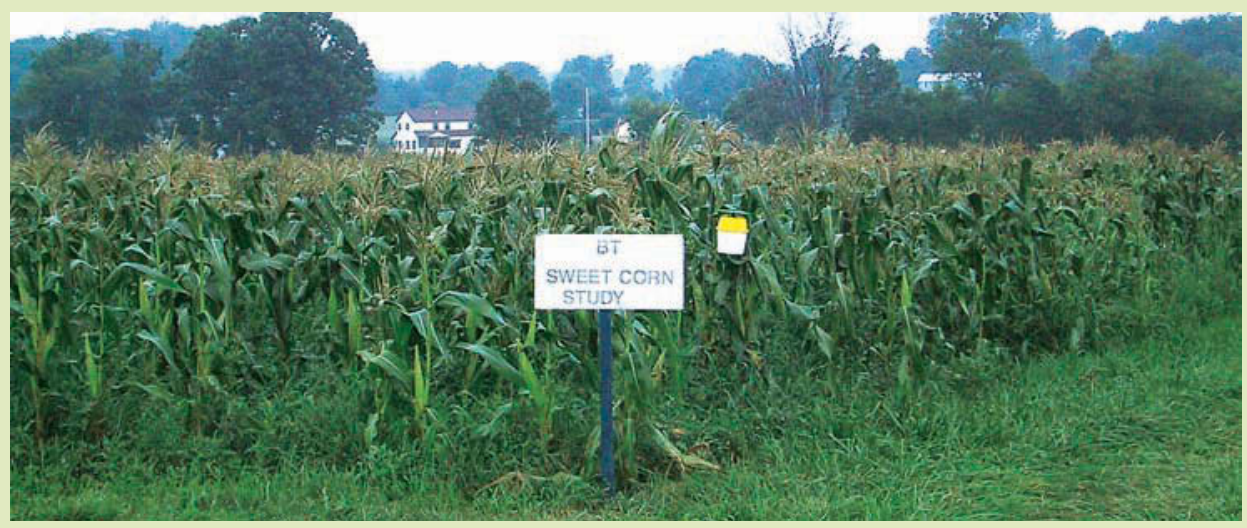

Results from a consumer-preference study in central Pennsylvania suggest that there may be a viable market for Bt sweet corn, above. 
willing to pay for labeling of GE foods if it increased the cost of their family's food by $\$ 50$ a year or more, but $44 \%$ were not willing to pay anything for the label information.

\section{Other food safety issues}

Some survey findings indicate consumer concern about biotech food relative to concerns about other food safety issues. On average, consumers seem to be more concerned about pesticide residues than biotechnology. For example, the 2001 Pew study asked how much respondents worried about several different food safety issues. About one-third said that biotechnology or biotech products were "one of the things that worries" them "most" or "a great deal" about food safety. However, this proportion was dwarfed by those who said chemicals and fertilizer use (46\%), Salmonella $(66 \%)$ and freshness $(71 \%)$ worried them "most" or "a great deal" (multiple responses were allowed). Similarly, the CSPI study found that 56\% of respondents thought food with imported ingredients should be labeled, and $43 \%$ thought labels should indicate whether crops were grown "using practices that cause farm soil erosion" (relative to $62 \%$ who thought GE ingredients should be indicated). These results indicate that looking at biotechnology in isolation is likely to overemphasize consumer concerns for many, it is just one of several food safety issues they think about.

\section{Experimental approaches}

While surveys indicate some variables that affect consumer decisions, an important aspect is usually omitted: the influence of prices and income. As the CSPI study showed, there is a big difference between asking people if they think biotech products should be labeled and asking them how much more they would be willing to pay for those labels. In addition, surveys are usually hypothetical in nature - respondents do not have to commit to actions that are consistent with their stated attitudes or preferences. In contrast, results

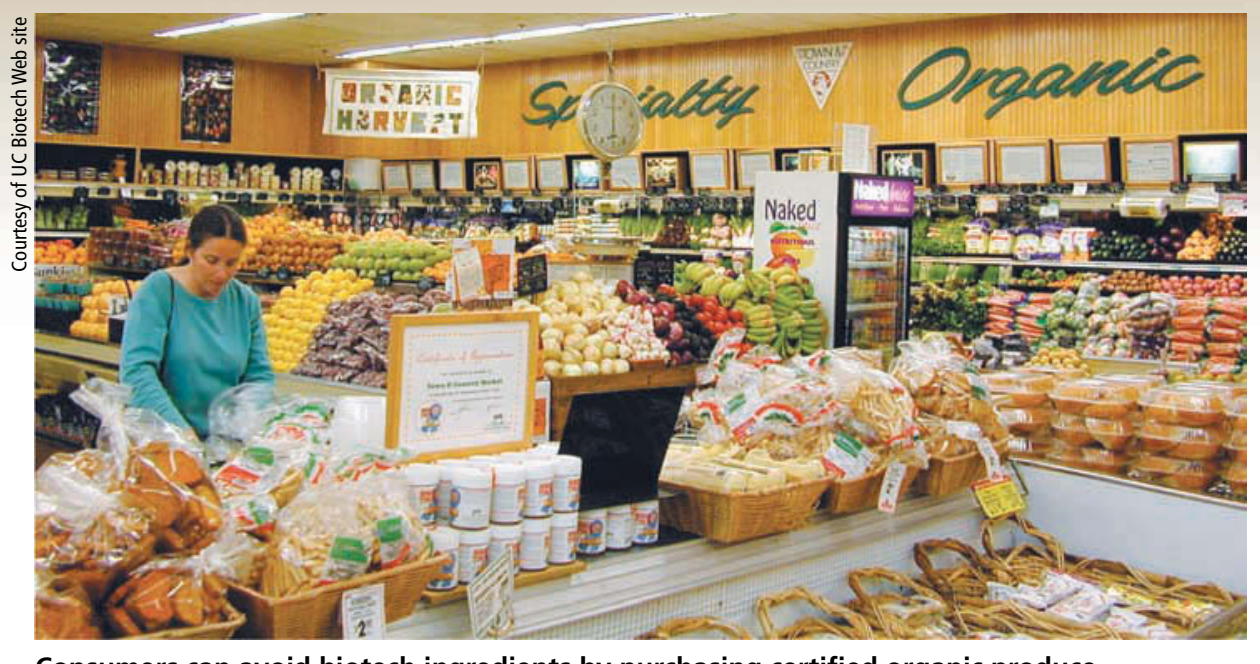

Consumers can avoid biotech ingredients by purchasing certified organic produce and foods, which cannot be grown using biotech crops. It is difficult to determine how important the absence of biotech ingredients is to consumers relative to other components of organic certification.

from experimental auctions, which incorporate purchases, have been shown to more closely approximate how consumers would behave in a market environment. In one type of auction, participants are brought to a common location, given some money and asked to bid on a product. After bids are collected, the "winning" bidders are determined, and they use the money received earlier to purchase the product being auctioned.

To date, only a few experimental auctions have been conducted that measure consumer valuation of biotech and nonbiotech food products. Tegene et al. (2003) conducted a series of 12 experimental auctions in 2001 in Des Moines, Iowa, and St. Paul, Minnesota. Participants were asked to bid on two sets of products, each including vegetable oil, tortilla chips and Russet potatoes. In one set, the products were labeled as made using genetic modification; in the other set, this label was omitted. On average, consumers bid $14 \%$ less for the biotech-labeled product. The participants in each auction were given one of six different sets of information that included either pro-biotech, anti-biotech or third-party objective information, or some combination. Not surprisingly, the difference in bids between the labeled and nonlabeled products was influenced by the type of information provided, with the largest difference occurring when participants received only negative information and vice versa.
Results from these auctions suggest some consumer resistance to biotech foods, but the influence of the information provided suggests that consumer resistance is somewhat malleable. Experimental auctions reflect onetime decisions, and may not represent repeat purchasing behavior. However, there is still great opportunity to learn about consumer preferences for biotech products using this method.

Another method is the market experiment, in which biotech and nonbiotech products are clearly labeled in a retail environment and consumer purchases are measured. These studies require retailer cooperation and a product suitable for study, which make them difficult to conduct. Two have been conducted using fresh-market sweet corn, by the University of Guelph (Powell et al. 2003) and Pennsylvania State University (see box, page 103). In these studies, biotech corn accounted for roughly $60 \%$ and $40 \%$ of the corn sold, respectively, indicating some degree of consumer acceptance.

\section{Making sense of consumer views}

The studies discussed do not show overwhelming opposition to biotech products, and yet consumer acceptance is still cited as a barrier to adoption or development of biotechnology. While there are no readily apparent explanations for this contradiction, survey results provide some insight; and despite methodological shortcomings and variations, important 


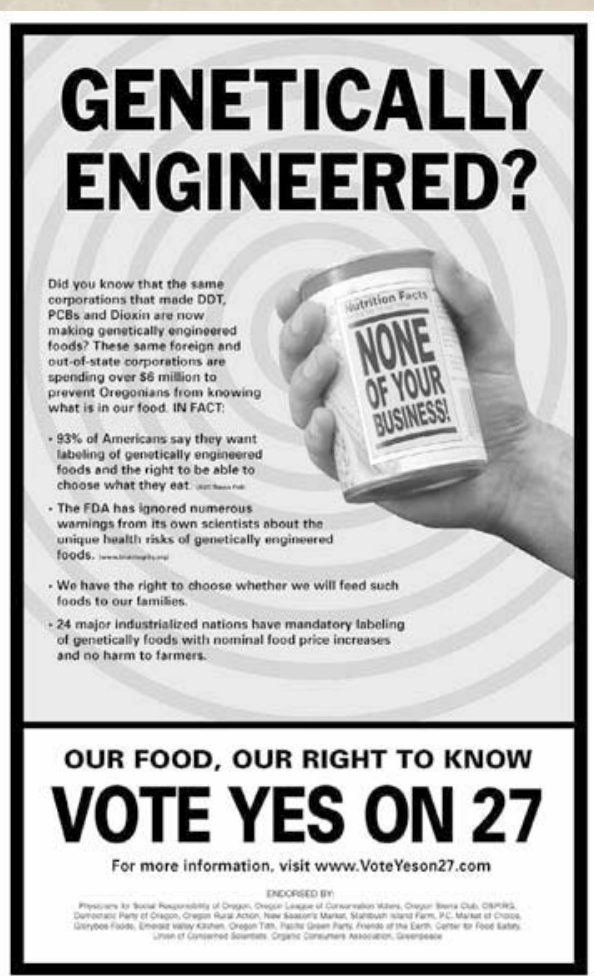

conclusions can be drawn. While some consumers are indifferent to the technology, the rest are split roughly half in favor and against biotech products, with a small share strongly opposed. When asked, most consumers say biotech products should be labeled. However, the most important and fairly consistent finding is that the majority of consumers are uninformed about biotechnology and, more generally, about how food is produced. Given these consumer characteristics, is biotechnology an aspect of the food system that should be consumer-driven?

If actions were taken to more closely align regulations with the stated preferences of consumers, would their subsequent actions be consistent with stated preferences? The debate about the use of recombinant bovine somatotropin (rbST), a growth hormone, in milk production provides a striking example to the contrary. While consumer surveys indicated sizable opposition to the use of rbST, there were no statistically significant changes in the demand for milk when the FDA approved its use (Aldrich and Blisard 1998). Consumers may say one thing but do another. Further, it is possible that consumer issues will fade once researchers stop asking consumers for their opinions about biotech products.
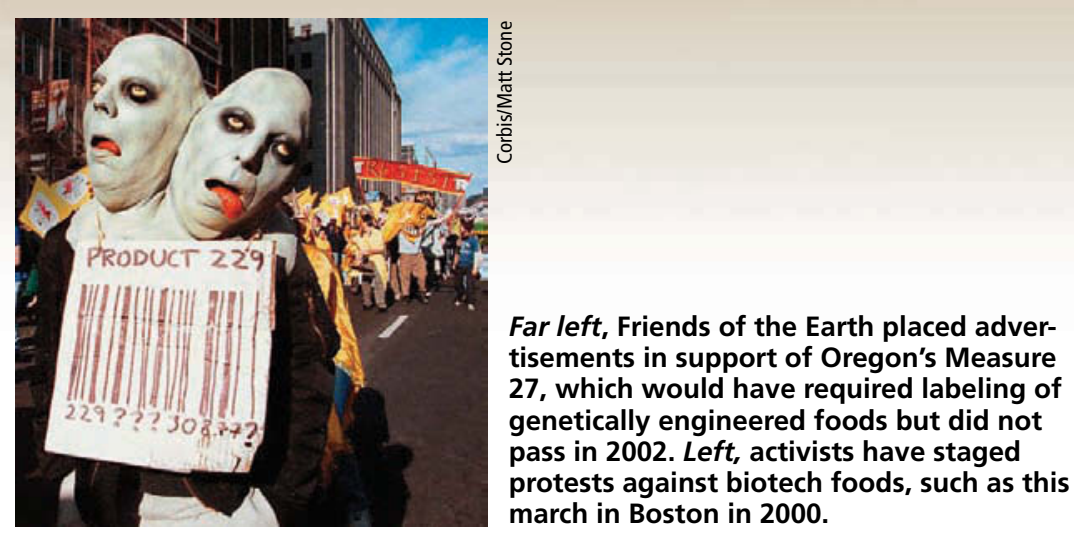

If Measure 27 on the 2002 Oregon ballot had passed (it did not) it would have provided mandatory labels on biotech foods, as well as an interesting opportunity to compare stated preferences with market behavior.

The small group that strongly opposes agricultural biotechnology is quite vocal. Anti-biotech activist groups such as Greenpeace and the GE Food Alert are adept at communicating with the public, and willing to use inflammatory language and theatrics, as seen in their Web sites (www.greenpeaceusa.org and www.gefoodalert. org) and public demonstrations. They may oppose agricultural biotechnology as a whole, but they often target individual companies (such as with mock company Web sites depicting products and brands as dangerous). Specific companies targeted may shift their focus from satisfying customers to avoiding negative publicity. Publicity stunts and negative information campaigns would have little effect on those who know about and understand the technology. The lack of consumer knowledge gives negative publicity campaigns their power.

While education is unlikely to settle the debate about the relative costs and benefits of agricultural biotechnology, it would at least enable consumers to understand the choices they make when they do their food shopping. Education poses a challenge because any educational materials must compete with a multitude of other messages totally unrelated to food or biotechnology. Further, messages about agricultural biotechnology are abundant, some are difficult for the layperson to understand and information presented by different sources is often contradictory. Govern- ment agencies and universities can play an important role in providing and disseminating objective and accessible information to consumers about biotechnology and food production.

\section{J.S. James is Assistant Professor of Agricul-} tural Economics, Department of Agricultural Economics and Rural Sociology, Pennsylvania State University, University Park, Penn.

\section{References}

Aldrich L, Blisard N. 1998. Consumer Acceptance of Biotechnology: Lessons from the rbST Experience. U.S. Department of Agriculture, Economic Research Service, Washington, DC. Ag Info Bull No 747-01.

[CSPI] Center for Science in the Public Interest. 2001. National Opinion Poll on Labeling of Genetically Engineered Foods. http:// cspinet.org/reports/op_poll_labeling.html.

[IFIC] International Food Information Council. 2003. U.S. Consumer Attitudes Toward Food Biotechnology. http://www.ific. org/research/biotechres03.cfm.

Pew Initiative on Food and Biotechnology. 2001. Public Sentiment About Genetically Modified Food. http://pewagbiotech. org/polls/.

Pew Initiative on Food and Biotechnology. 2003. An Update on Public Sentiment About Agricultural Biotechnology. http:// pewagbiotech.org/polls/.

Powell DA, Blaine K, Morris S. 2003. Agronomic and consumer considerations for Bt and conventional sweet-corn. Brit Food J 105:700-13.

Saad L. 2001. Biotech food remains fairly obscure to most Americans. Gallup Poll Monthly (August):38-41.

Shanahan J, Scheufele D, Lee E. 2001. Attitudes about agricultural biotechnology and genetically modified organisms. Public Opinion Quarterly 65:267-81.

Tegene A, Huffman WE, Rousu M, Shogren JF. 2003. The Effects of Information on Consumer Demand for Biotech Foods: Evidence from Experimental Auctions. U.S. Department of Agriculture, Economic Research Service, Washington, DC. Tech Bull No 1903. 